\title{
The Clinicians' Satisfaction with Clinical Pathway Implementation: Preliminary Development of an Assessment Scale in China
}

This article was published in the following Dove Press journal: Risk Management and Healthcare Policy

\author{
Junlong $\mathrm{Li}^{1, *}$ \\ Kui Shen ${ }^{1} *$ \\ Jun $\mathrm{Hu}^{2}$ \\ Xinyue $\mathrm{Li}^{3}$ \\ Jie Liu' \\ Yonghong Du' \\ Kang Huang ${ }^{4}$
}

'Sichuan Vocational College of Health and Rehabilitation, Zigong, Sichuan, People's Republic of China; ${ }^{2}$ Health Information Center of Zigong, Sichuan, People's Republic of China; ${ }^{3}$ Finance Department, Zigong Fourth People's Hospital, Zigong, Sichuan, People's Republic of China; ${ }^{4}$ Health Commission of Zigong, Zigong, Sichuan, People's Republic of China

*These authors contributed equally to this work
Correspondence: Kang Huang

Health Commission of Zigong, Hua Yuan Street 66, Zigong 643000, People's

Republic of China

Tel +86 I3990043323

Email seven-lee@foxmail.com
Purpose: To develop a satisfaction scale of Chinese clinicians with Clinical Pathway (CP) implementation and evaluate its validity, reliability and item discrimination.

Materials and Methods: Literature review, in-person interviews, and Delphi were used to design the scale. Data were collected in two phases using random sampling on the spot and an online survey. In the first phase, data from 239 clinicians were investigated in exploratory factor analysis. In the second phase, 513 valid questionnaires were collected and used for confirmatory factor analysis.

Results: The scale developed in this study has three dimensions (organization support, process identity, and effect perception) and a total of 21 items. Cronbach's alpha of each dimension was higher than 0.9 . The 3 -factor model had enough fitness $(\chi 2 / \mathrm{df}=5.602, \mathrm{NFI}=$ 0.926, $\mathrm{IFI}=0.938, \mathrm{CFI}=0.938, \mathrm{RFI}=0.914, \mathrm{TLI}=0.929, \mathrm{RMSEA}=0.095, \mathrm{RMR}=0.045)$. The standardized factor loadings of 21 variables were between 0.742 and 0.949 . The average variance extracted (AVE) of each dimension was higher than 0.7 , and the construct reliability (CR) of the dimensions was higher than 0.9. The Chi-square difference test results showed that the difference value between the unlimited and limited model of each two potential constructs was higher than $3.84(\mathrm{P}<0.001)$.

Conclusion: The clinicians' satisfaction scale developed in this study has good construct validity, convergent validity, discriminant validity, internal consistency, and item discrimination. This suggests its usefulness as a tool to assess the satisfaction of clinicians in the implementation of CP in China.

Keywords: clinicians, clinical pathway, satisfaction, scale development

\section{Introduction}

Clinical Pathway (CP) is an interdisciplinary and comprehensive management mode of clinical treatment. It is a standardized service plan designed by a group of multidisciplinary professionals, including clinicians, nurses, pharmacists, medical technicians, and hospital managers for patients with specific diseases. The plan sets the most appropriate and rigorous work order, involving monitoring, treatment, care, recovery, and other links. Each link has the appropriate time required to reduce waste of resources and yet gives patients the best medical care. ${ }^{1-3}$ CP originated in America in the 1970s. ${ }^{4}$ In 1985 , it was named Critical Pathway and first implemented by the New England Medical Center in Boston. Researchers in the New England Medical Center observed that poor-quality medical service was often related to improper and 
unconventional clinical practice, and that outcomes significantly improved after implementing CP. Afterwards, the promotion and application of $\mathrm{CP}$ gradually started to spread in America. In the 1990s, countries in different regions of the world, such as Spain, New Zealand, and South Africa, began to experiment with CP implementation, followed by Japan, Singapore, and other Asian countries. ${ }^{5}$

In 2009, China's Ministry of Health printed and distributed the Notice on Pilot Work of CP Management and the Guiding Principles of $\mathrm{CP}$ Management (Trial). ${ }^{6,7}$ The Chinese government has further strengthened the promotion of $\mathrm{CP}$ in the new phase of healthcare system reform. In 2015, the Action Plan for further Improvement of Medical Service, issued by China's Health and Family Planning Commission, stated that all tertiary referral hospitals and $80 \%$ of secondary referral hospitals have to implement CP management. ${ }^{8}$ From 2009 to 2019, the number of CPs published by the National Health Commission of the People's Republic of China has reached 1212. ${ }^{9}$ The promotion and application of CP has a profound and positive effect on promoting medical quality, improving patients' satisfaction, and enhancing the doctor-patient relationship. However, promotion of CP faces several challenges. Some clinicians believe that standardization of diagnosis and treatment behavior restrain innovative thinking, restrict medical autonomy, and the ability to make decisions. Also, some clinicians believe that lowering medical cost will negatively impact their personal income, and therefore they resist the implementation of CP. ${ }^{10}$ Given the key role that clinicians play in promoting and applying $\mathrm{CP}$, their attitude towards $\mathrm{CP}$ will directly affect its application. Studies have shown that clinicians with a high level of training, recognition, and satisfaction benefit from the CP implementation. As early as 2011, China's Ministry of Health issued the implementation rules for tertiary general hospitals to improve healthcare delivery, which required hospitals to investigate satisfaction of the clinicians with $\mathrm{CP}$ implementation. ${ }^{11}$ Currently, local research focuses on patients' satisfaction with $\mathrm{CP}$, and only a few investigate clinicians' satisfaction. To our knowledge, only Wang et al. conducted a single factor analysis of factors influencing satisfaction of medical staff with $\mathrm{CP}$ implementation. ${ }^{10}$ Therefore, there is a need to study the satisfaction of clinicians with the implementation of CP and the influencing factors, especially in China, where information on this topic is lacking.

In view of this, this study aims to develop a satisfaction scale of Chinese clinicians with $\mathrm{CP}$ implementation and evaluate its validity, reliability, and item discrimination. The ultimate goal is to provide a theoretical basis for research on the influencing factors of clinicians' satisfaction with $\mathrm{CP}$ implementation and offer practical reference to $\mathrm{CP}$ management for hospitals in China.

\section{Materials and Methods Scale Compilation}

We initially interviewed clinicians who participated in $\mathrm{CP}$ implementation and collected their views on $\mathrm{CP}$ implementation and its structural features. These interviews were guided by a literature review of influencing factors of clinicians' satisfaction with $\mathrm{CP}$ implementation. After this step, specific items for measuring clinicians' satisfaction with $\mathrm{CP}$ implementation were created. In creating these items, we considered the health administration institutions' and hospitals' organizational structure, operating mechanism, and regulations. Four experts were invited to modify and improve the designed items: a medical doctor (attending physician or above, who had participated in the implementation of CP for more than five years), a public health professor (research focus on quality management in healthcare), a quality management in healthcare specialist (head of quality management in healthcare department), and a health administration official (with expertise in CP management). Finally, a 24-item scale was developed, and the Likert five-point scoring method was employed (Table 1). Scores of 1, 2, 3, 4, and 5 represented strongly dissatisfied, dissatisfied, not sure, satisfied, and strongly satisfied, respectively.

\section{Data Collection}

Data collection consisted of two phases. Data acquired in the first phase was used for Exploratory Factor Analysis (EFA) of the initial scale. In this phase, a random sample of 239 valid questionnaires was collected from a public tertiary hospital in Sichuan Province. In the second phase, 513 valid questionnaires were collected using the online network questionnaire platform "Sojump" for Confirmatory Factor Analysis (CFA) of the scale. The descriptive statistics for the two phases are shown in Table 2. 
Table I Initial Scale of Clinicians' Satisfaction with CP Implementation

\begin{tabular}{|c|c|}
\hline Num & Items \\
\hline QI & The hospital carried out sufficient training for CP implementation. \\
\hline Q2 & The hospital has good incentives in CP implementation. \\
\hline Q3 & The hospital has a sound management system in CP implementation. \\
\hline Q4 & The hospital leaders attach great importance to $\mathrm{CP}$ implementation. \\
\hline Q5 & The hospital's evaluation index of CP implementation is scientific and rational. \\
\hline Q6 & The level of hospital communication can support the implementation of $\mathrm{CP}$ well. \\
\hline Q7 & Functional departments provided good services for CP implementation. \\
\hline Q8 & $\mathrm{CP}$ is implemented under scientific and rational supervision of functional departments. \\
\hline Q9 & The implementation of $\mathrm{CP}$ is evaluated scientifically and reasonably by functional departments. \\
\hline Q10 & Medical technique departments offered sufficient support for CP implementation. \\
\hline QII & Your department attaches great importance to CP implementation. \\
\hline Q12 & The internal CP management of your department is rational and efficient. \\
\hline Q13 & In your department, doctors and nurses work with tacit cooperation in the process of implementing CP. \\
\hline Q14 & The implementation of the treatment plan of $\mathrm{CP}$ is very reasonable. \\
\hline Q15 & The texts of diseases of CP implementation are very thorough. \\
\hline Q16 & The medical personnel give full play to their medical abilities after implementing CP. \\
\hline Q17 & The medical personnel's workload has been reduced after implementing CP. \\
\hline Q18 & Diagnosis and treatment of diseases become more convenient after implementing $\mathrm{CP}$. \\
\hline Q19 & The work efficiency of medical personnel has been obviously improved after implementing CP. \\
\hline Q20 & The compliance of CP implementation in your department is good. \\
\hline Q21 & The income of medical personnel increased significantly after implementing $\mathrm{CP}$. \\
\hline Q22 & Diagnosis and treatment behaviors can be regulated better in CP implementation. \\
\hline Q23 & The implementation of $\mathrm{CP}$ is positive in ensuring medical safety. \\
\hline Q24 & The implementation of CP can significantly improve doctor-patient relationship. \\
\hline
\end{tabular}

\section{Statistical Analysis}

All analyses were processed using SPSS19.0 and AMOS17.0. Item discrimination was tested using the index of Discrimination (D), critical ratio, and Corrected Item-Total Correlation (CITC). Factor analysis was used for EFA to select items and reduce dimensionality. Structural equation model (SEM) was used for CFA to verify the construct validity, convergent validity, and discriminant validity of the scale. Cronbach's Alpha was used to test the reliability of the scale. The results were statistically significant if $\mathrm{P}<0.05$ (two-tailed).

\section{Results}

\section{Item Analysis}

Before carrying out EFA, item analysis was employed. Participants who ranked at the top 27th percentile among those who participated in the first phase of the survey constituted the high-score group, while those who ranked in the bottom 27th percentile constituted the low-score group. The discrimination index was defined as the difference between the scoring rate of the high-score group and the low-score group. The critical ratio was obtained by examining the difference in each item's average score between higher and lower groups with independent-samples $t$-test. Additionally, CITC was also investigated (Table 3). As shown in Table 3, each item displayed strong discrimination and, hence, should not be deleted $(\mathrm{D}>0.2$, CITC $>$ 0.3 , critical ratio was significant). ${ }^{12-14}$

\section{Exploratory Factor Analysis}

Factor analysis is adopted to evaluate the structure of a set of variables, especially in developing a scale. This gives insights into the relationship between the developed scale and its potential variables. ${ }^{15} \mathrm{EFA}$ is usually carried out in the early stage of research, providing tools for integrating variables and generating hypotheses about the underlying processes. ${ }^{16}$

The Kaiser-Meyer-Olkin (KMO) test and Bartlett's test of sphericitywere initially utilized to test the correlation among the 24 items. The results demonstrated that KMO was 0.955 , which was higher than 0.9. According to the Kaiser-Guttman rule, this means a strong 
Table 2 Descriptive Statistics for Two-Phases Data Collection

\begin{tabular}{|c|c|c|c|c|c|}
\hline \multirow[t]{2}{*}{ Features } & \multirow[t]{2}{*}{ Basic Information } & \multicolumn{2}{|c|}{ The Ist Phase } & \multicolumn{2}{|c|}{ The 2nd Phase } \\
\hline & & Number & Proportion (\%) & Number & Proportion (\%) \\
\hline \multirow[t]{2}{*}{ Gender } & Male & 154 & 64.4 & 269 & 52.4 \\
\hline & Female & 85 & 35.6 & 244 & 47.6 \\
\hline \multirow[t]{4}{*}{ Age } & $<30$ & 60 & 25.1 & 115 & 22.4 \\
\hline & $30-39$ & 105 & 43.9 & 262 & $5 \mathrm{I} .1$ \\
\hline & $40-49$ & 51 & 21.3 & 88 & 17.2 \\
\hline & $\geq 50$ & 23 & 9.6 & 48 & 9.4 \\
\hline \multirow[t]{4}{*}{ Education background } & (Under) Junior College & 12 & 5 & 40 & 7.8 \\
\hline & Bachelor & 136 & 56.9 & 377 & 73.5 \\
\hline & Master & 89 & 37.2 & 89 & 17.3 \\
\hline & Doctor & 2 & 0.8 & 7 & 1.4 \\
\hline \multirow[t]{5}{*}{ Professional \& Technical posts } & None & 29 & 12.1 & 20 & 3.9 \\
\hline & Primary & 60 & 25.1 & 165 & 32.2 \\
\hline & Intermediate & 66 & 27.6 & $|8|$ & 35.3 \\
\hline & Associate professor & 73 & 30.5 & 123 & 24 \\
\hline & Professor & 11 & 4.6 & 24 & 4.7 \\
\hline \multirow[t]{5}{*}{ Working years } & $<5$ & 80 & 33.5 & 109 & 21.2 \\
\hline & $5-9$ & 45 & 18.8 & 157 & 30.6 \\
\hline & $10-19$ & 67 & 28 & $|4|$ & 27.5 \\
\hline & $20-29$ & 32 & 13.4 & 77 & 15 \\
\hline & $\geq 30$ & 15 & 6.3 & 29 & 5.7 \\
\hline
\end{tabular}

correlation existed among those 24 items. ${ }^{17}$ Moreover, this means that the sample size of our study was sufficient for the items of the scale. ${ }^{18}$ Bartlett's test of sphericityrevealed that the correlation matrix of variables was not a unit matrix $\left(\chi^{2}=7128.431, \mathrm{P}=\right.$ $0.000)$. That is, items in the scale were correlated with each other. ${ }^{19}$ These results indicate the appropriateness to further conduct factor analysis.

\section{First EFA}

The first EFA was used to screen out the items. Principal component analysis was used to conduct factor analysis of the scale. Based on the Kaiser-Guttman rule, factors whose eigenvalue was higher than 1 were extracted, and three common factors were obtained. The varimax rotation showed that the total variation of accumulative explained variance was $79.76 \%$ (Table 4). In light of item deletion criteria that communality was less than 0.3 and the factor loadings were less than 0.4 , or the same loadings exist between two or more factors (differences between them should be less than 0.2), ${ }^{20}$ items Q10, Q15, and Q20 were removed. Then, a scale containing 3 common factors and 21 items was constructed.

\section{Second EFA}

The second phase of EFA was used for dimensionality reduction. As shown in Table 5, KMO was 0.950, Bartlett's test of sphericity was significant $(\mathrm{P}<0.001)$, the factor loading of each item on its corresponding dimension ranged from 0.652 to 0.894 , communality was greater than 0.3 , the total variance of accumulative interpretation was $80.95 \%$, and Cronbach's alpha of each dimension was higher than 0.9 .

A scale containing 3 common factors and 21 items was constructed. According to the designed dimensions in the initial scale, three common factors were named. The first common factor was "effect perception," reflecting the effects of $\mathrm{CP}$ implementation, which comprised 8 items (Q16, Q17, Q18, Q19, Q21, Q22, Q23, and $\mathrm{Q}$ 24). The second common factor 2, which revealed the level of support from various organizations during CP implementation, was "organization support" and consisted of 9 items (Q1, Q2, Q3, Q4, Q5, Q6, Q7, Q8, Q9). Common factor 3 was regarded as "process 
Table 3 Results of Discrimination Analysis of the Scale

\begin{tabular}{|c|c|c|c|}
\hline Items & D & CITC & Critical Ratio \\
\hline QI. The hospital carried out sufficient training for CP implementation. & 0.280 & 0.709 & $12.20 \mid * * *$ \\
\hline Q2. The hospital has good incentives in CP implementation. & 0.289 & 0.684 & $10.688 * * *$ \\
\hline Q3. The hospital has a sound management system in CP implementation. & 0.298 & 0.752 & $12.008 * * *$ \\
\hline Q4. The hospital leaders attach great importance to CP implementation. & 0.249 & 0.715 & II.594*** \\
\hline Q5. The hospital's evaluation index of CP implementation is scientific and rational. & 0.400 & 0.794 & $15.643 * * *$ \\
\hline Q6. The level of hospital communication can support the implementation of CP well. & 0.428 & 0.797 & $13.972 * * *$ \\
\hline Q7. Functional departments provided good services for CP implementation. & 0.437 & 0.846 & $18.285^{* * *}$ \\
\hline Q8. CP is implemented under scientific and rational supervision of functional departments. & 0.378 & 0.819 & $15.447 * * *$ \\
\hline Q9. The implementation of CP is evaluated scientifically and reasonably by functional departments. & 0.394 & 0.852 & $15.406 * * *$ \\
\hline QI0. Medical technique departments offered sufficient support for CP implementation. & 0.406 & 0.841 & $18.191 * * *$ \\
\hline QII. Your department attaches great importance to CP implementation. & 0.237 & 0.613 & $9.146 * * *$ \\
\hline QI2. The internal CP management of your department is rational and efficient. & 0.317 & 0.702 & $11.166 * * *$ \\
\hline QI3. In your department, doctors and nurses work with tacit cooperation in the process of implementing CP. & 0.323 & 0.706 & II.549*** \\
\hline Q14. The implementation of the treatment plan of $C P$ is very reasonable. & 0.332 & 0.763 & $13.860 * * *$ \\
\hline QI5. The texts of diseases of CP implementation are very thorough. & 0.403 & 0.797 & $14.450 * * *$ \\
\hline Q16. The medical personnel give full play to their medical abilities after implementing $C P$. & 0.520 & 0.865 & $21.234 * * *$ \\
\hline QI7. The medical personnel's workload has been reduced after implementing CP. & 0.597 & 0.790 & $25.104 * * *$ \\
\hline QI8. Diagnosis and treatment of diseases become more convenient after implementing CP. & 0.591 & 0.846 & $25.265^{* * *}$ \\
\hline Q19. The work efficiency of medical personnel has been obviously improved after implementing CP. & 0.588 & 0.828 & $26.321 * * *$ \\
\hline Q20. The compliance of CP implementation in your department is good. & 0.378 & 0.804 & $16.57 \mid * * *$ \\
\hline Q2I. The income of medical personnel increased significantly after implementing CP. & 0.578 & 0.718 & $22.346 * * *$ \\
\hline Q22. Diagnosis and treatment behaviors can be regulated better in CP implementation. & 0.474 & 0.839 & $20.579 * * *$ \\
\hline Q23. The implementation of CP is positive in ensuring medical safety. & 0.480 & 0.810 & $19.857^{* * *}$ \\
\hline Q24. The implementation of $C P$ can significantly improve doctor-patient relationship. & 0.529 & 0.810 & $20.768 * * *$ \\
\hline
\end{tabular}

Note: $* * *$ Denote I\% significance level.

identity" and contained 4 items (Q11, Q12, Q13, Q14), displaying the degree of recognition or acceptance of $\mathrm{CP}$ implementation.

\section{Confirmatory Factor Analysis Model Fit Statistics of CFA}

Confirmatory Factor Analysis (CFA) was used to explore the fitting degree of the conceptual model and actual data, convergent validity, and discriminant validity of the conceptual model. CFA was conducted by building a structural equation model based on the second-phase survey data According to the results of EFA, a model involving first order and three factors was established to test clinicians' satisfaction with CP implementation. The revised model is shown in Figure $1\left(\chi^{2} / \mathrm{df}=5.602, \mathrm{NFI}=0.926, \mathrm{IFI}=0.938\right.$, $\mathrm{CFI}=0.938, \mathrm{RFI}=0.914, \mathrm{TLI}=0.929, \mathrm{RMSEA}=0.095$, $\mathrm{RMR}=0.045$ ).

The results of the structural equation three-factor model demonstrated that the standard factor loading of each entry on their respective dimensions was between 0.742 and 0.949 , and the error variation in the model was positive. It indicated that the basic fit index of the first-order three-factor verification model of clinician's CP satisfaction met the test standard and did not violate the model identification rules. In the model fit index, NFI, IFI, CFI, RFI, and TLI values were greater than 0.9, RMSEA $<$ $1, \mathrm{RMR}<0.05$; all met the reference standard, while $\chi^{2} / \mathrm{df}$ $>5$, slightly higher than the reference standard. ${ }^{21}$ According to Zhonglin Wen and others, the $\chi^{2} / \mathrm{df}$ value is affected by the sample size. When the sample size is large, it cannot be used as a criterion to judge whether the model fits. ${ }^{22}$ The second phase of this study included a larger sample size of 513, and hence, $\chi^{2} / \mathrm{df}$ could be ruled out as a model fit test index. Therefore, it can be assumed that the first-order three-factor verification factor model of clinician's CP satisfaction was well adapted to the actual observation data, the overall fit of the model was perfect, and the scale had good construct validity.

\section{Convergent Validity}

To evaluate convergent validity of the model, factor loadings, AVE, and CR were calculated (Table 6). As shown in 
Table 4 EFA of the Initial Scale

\begin{tabular}{|c|c|c|c|c|}
\hline Items & Factor I & Factor 2 & Factor 3 & Communalities \\
\hline Q19. Clinicians' work efficiency was significantly improved after implementing CP. & 0.889 & & & 0.898 \\
\hline QI7. Clinician's workloads was significantly reduced after implementing $C P$. & 0.886 & & & 0.867 \\
\hline Q18. CP implementation made it more convenient for clinicians to launch clinical activities. & 0.860 & & & 0.883 \\
\hline Q24. The doctor-patient relationship was significantly improved after implementing CP. & 0.831 & & & 0.821 \\
\hline Q21. Clinicians' income was significantly improved after implementing CP. & 0.810 & & & 0.732 \\
\hline Q23. CP implementation was positive in ensuring medical safety. & 0.802 & & & 0.795 \\
\hline Q22.Diagnosis and treatment behaviors can be regulated better in CP implementation. & 0.775 & & & 0.818 \\
\hline Q16.Clinicians gave full play to their medical abilities after implementing CP. & 0.732 & & & 0.808 \\
\hline Q20.Clinicians in your department have good compliance in CP implementation. & 0.574 & & 0.529 & 0.726 \\
\hline Q3. The hospital has a sound management system in CP implementation. & & 0.799 & & 0.798 \\
\hline Q2.The hospital has good incentives in CP implementation. & & 0.784 & & 0.752 \\
\hline Q5. The hospital's evaluation index of CP implementation is scientific and rational. & & 0.770 & & 0.794 \\
\hline Q4. Hospital leaders attach great importance to $\mathrm{CP}$ implementation. & & 0.755 & & 0.766 \\
\hline Q8. Functional departments conducted scientific and rational supervision in CP implementation. & & 0.751 & & 0.805 \\
\hline Q6. The level of hospital communication can support the implementation of CP well. & & 0.743 & & 0.782 \\
\hline Q7. Functional departments provided good services for CP implementation. & & 0.739 & & 0.836 \\
\hline QI. The hospital carried out sufficient training for $\mathrm{CP}$ implementation. & & 0.730 & & 0.695 \\
\hline Q9. Functional departments' evaluation of CP implementation was scientific and reasonable. & & 0.725 & & 0.824 \\
\hline Q10. Medical technique departments offered sufficient support for CP implementation. & 0.499 & 0.583 & 0.400 & 0.750 \\
\hline Q13. In your department, doctors and nurses work with tacit cooperation in the process of implementing CP. & & & 0.843 & 0.871 \\
\hline Q12. The internal CP management of your department is rational and efficient. & & & 0.829 & 0.855 \\
\hline QII. Your department attaches great importance to CP implementation. & & & 0.822 & 0.799 \\
\hline Q 14. Treatment plans of CP implementation are very rational. & & & 0.672 & 0.744 \\
\hline Q15. The texts of diseases of CP implementation are pretty thorough. & 0.486 & & 0.572 & 0.723 \\
\hline Eigenvalue & 15.433 & 2.312 & 1.396 & \\
\hline Explained Variance & 32.171 & 28.657 & 18.928 & \\
\hline
\end{tabular}

Table 6, the standardized factor loadings of 21 variables were between 0.742 and 0.949 . The AVE of effect perception, organization support, and process identity were $0.783,0.727$, and 0.766 , respectively, and the CR were $0.960,0.929$, and 0.966 , respectively. The model had a strong convergent validity (all standardized factor loadings $>0.7$, all AVE $>0.5$, all $\mathrm{CR}>0.7){ }^{23,24}$

\section{Discriminant Validity}

Discriminant validity among process identity, organization support, and effect perception were assessed by chi-square difference test (Table 7). If the difference value between the unlimited and limited model of each two potential constructs was higher than the test index (3.84) of discriminant validity of critical factor construct, the difference was considered non-significant $(\mathrm{P}<0.05)$. That is to say, the hypothesis that there is a highly positive correlation $(\rho=1)$ between each two constructs is denied, and a significant difference exists between each two constructs. Thus, the discriminant validity of each two constructs is perfect. ${ }^{25}$ As shown in Table 7, the model reveals perfect discriminant validity since the difference value between the unlimited and limited model of each two potential constructs was higher than 3.84 (505.550, 42.657, and 77.838, respectively), denoting a significant difference $(\mathrm{P}<0.001)$.

\section{Reliability and Item Discrimination}

The internal consistency and item discrimination of the scale were examined (Table 8). As shown in Table 8, Cronbach's Alpha of organization support, process identity, and effect perception were higher than $0.9(0.960,0.927$, and 0.965 , respectively). This indicates that the scale possesses excellent internal consistency. ${ }^{26}$ Additionally, we observed perfect item discrimination of the scale $(\mathrm{D}>0.2$, CITC $>0.5$, critical ratio was significant).

\section{Discussion}

Based on Kevser Özdemir's suggestions for scale development, ${ }^{27}$ literature review and expert consultations are needed to determine the appropriateness of the items when setting up the scale. Also, data should be collected from different sample groups for evaluation required in the set of 
Table 5 EFA of the Initial Scale After Items Selection

\begin{tabular}{|c|c|c|c|c|}
\hline Items & Factor I & Factor 2 & Factor 3 & Communalities \\
\hline Q19. Clinicians' work efficiency was significantly improved after implementing CP. & 0.894 & & & 0.906 \\
\hline Q17. Clinician's workloads was significantly reduced after implementing CP. & 0.890 & & & 0.871 \\
\hline Q18. CP implementation made it more convenient for clinicians to launch clinical activities. & 0.864 & & & 0.889 \\
\hline Q24.The doctor-patient relationship was significantly improved after implementing CP. & 0.834 & & & 0.822 \\
\hline Q21. Clinicians' income was significantly improved after implementing CP. & 0.813 & & & 0.738 \\
\hline Q23. CP implementation was positive in ensuring medical safety. & 0.807 & & & 0.799 \\
\hline Q22. Diagnosis and treatment behaviors can be regulated better in $\mathrm{CP}$ implementation. & 0.781 & & & 0.820 \\
\hline Q16. Clinicians gave full play to their medical abilities after implementing CP. & 0.734 & & & 0.802 \\
\hline Q3. The hospital has a sound management system in CP implementation. & & 0.800 & & 0.802 \\
\hline Q5. The hospital's evaluation index of CP implementation is scientific and rational. & & 0.783 & & 0.804 \\
\hline Q2. The hospital has good incentives in CP implementation. & & 0.780 & & 0.756 \\
\hline Q8. Functional departments conducted scientific and rational supervision in CP implementation. & & 0.758 & & 0.804 \\
\hline Q6. The level of hospital communication can support the implementation of CP well. & & 0.748 & & $0.78 \mathrm{I}$ \\
\hline Q4. Hospital leaders attach great importance to CP implementation. & & 0.747 & & 0.773 \\
\hline Q7. Functional departments provided good services for CP implementation. & & 0.746 & & 0.833 \\
\hline Q9. Functional departments' evaluation of CP implementation was scientific and reasonable. & & 0.739 & & 0.826 \\
\hline QI.The hospital carried out sufficient training for CP implementation. & & 0.725 & & 0.693 \\
\hline Q13. In your department, doctors and nurses work with tacit cooperation in the process of implementing CP. & & & 0.839 & 0.875 \\
\hline QII.Your department attaches great importance to CP implementation. & & & 0.834 & 0.822 \\
\hline Q12. The internal CP management of your department is rational and efficient. & & & 0.821 & 0.852 \\
\hline Q14. Treatment plans of $\mathrm{CP}$ implementation are very rational. & & & 0.652 & 0.734 \\
\hline Eigenvalue & 13.382 & 2.302 & 1.316 & \\
\hline Explained Variance & 33.272 & 30.156 & 17.523 & \\
\hline Cronbach's Alpha & 0.968 & 0.959 & 0.923 & \\
\hline
\end{tabular}

items. This study was developed and revised following all of these suggestions. We interviewed clinicians individually to improve the accuracy and appropriateness of items. Besides, the scale was evaluated by EFA and CFA. Thus, we believe that our research design is robust. We decided to use factor analysis to select items and reduce dimensionality. Factor analysis makes factor variables more interpretable and has high naming clarity through rotation. Multiple correspondence analysis is mostly used to process the rows and columns of contingency table data, and represents the relationship between rows and columns in the data table with lowdimensional graphics. Factor analysis is more used in scale development. SEM is widely used in validity tests and is recognized by many scholars. Therefore, the methods used in the statistical analysis of this study are appropriate and fit the purpose.

\section{Validity and Reliability}

Based on literature review, individual interviews, and expert consultation, the present study developed a 24 -item scale to measure clinicians' satisfaction with $\mathrm{CP}$ implementation in China. Through the first phase of data collection, 21 items in the initial scale were selected and divided into three dimensions based on item analysis and EFA. In the second phase, CFA was adopted to determine the construct validity, convergent validity, discriminant validity, and scale reliability. The results demonstrated perfect internal consistency, construct validity, convergent validity, and discriminant validity, indicating that the scale possessed good internal quality and stable measurement structure.

\section{Structure of Scale}

The developed scale comprised three dimensions: organization support, process identity, and effect perception.

The dimension of organizational support reflects clinicians' perception of hardware support (such as technology, environment, software, and policy), emotion, software support by hospital leadership, and functional management during the implementation of $\mathrm{CP}$ management. These perceptions reflect whether the organizational structure and operational structure of the hospital to implement the $\mathrm{CP}$ are reasonable, and whether the hospital attaches importance to and pays attention to the attitude of clinicians in the process of implementing the CP. According to the theory of social exchange, the relationship between employees and organizations follows the 


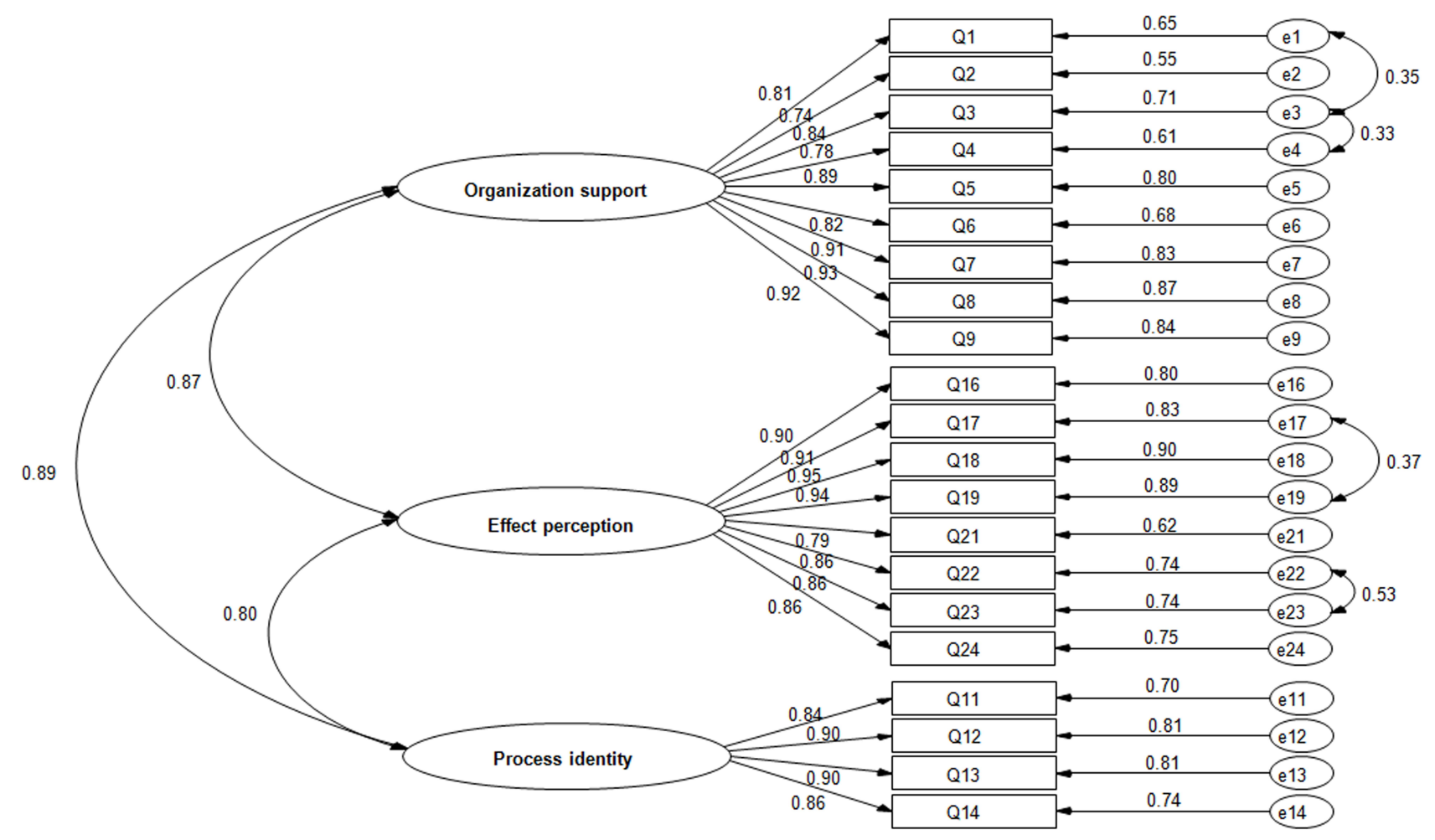

Figure I One order three factors model of clinicians' satisfaction with $\mathrm{CP}$ implementation.

principle of reciprocity. That is to say, when employees perceive support, care, and help from the organization, employees will respond positively to the organization. They will show better satisfaction in their work and more actively participate in organizational work. There is also evidence from current research indicating that employees with a high sense of organizational support have a positive work attitude and higher satisfaction. Therefore, doctors' perception of organizational support is an important factor in evaluating the satisfaction of $\mathrm{CP}$ implementation.

The dimension of process identity mainly reflects the clinicians' recognition of the internal management and operation of the department and the treatment plan of the $\mathrm{CP}$ in the process of implementing the $\mathrm{CP}$. It is the clinicians' perception of the practicability, rationality, and fluency of the implementation of the $\mathrm{CP}$, whether the internal operation mechanism of the department is efficient, whether the cooperation between doctors and nurses is tacit, and whether the path scheme is reasonable and other process factors can affect the smooth implementation of CP. If there are challenges in the implementation process of $\mathrm{CP}$, the clinicians' perception of the implementation process will be transformed into tension and pressure.
According to the theory of burnout, when employees cannot effectively deal with the stress and tension at work, they will produce a comprehensive symptom of emotional exhaustion, personality disintegration, and a low sense of achievement, all of which lead to the rapid consumption of emotional resources and a huge psychological gap. This will result in the phenomenon of lack of enthusiasm, job satisfaction decline, and work inefficiency, which will affect the development of CP work.

The dimension of effect perception mainly reflects the clinicians' perception of their own work efficiency, diagnosis and treatment behavior, economic benefits, and the levels of change in the quality of care and doctor-patient relationship after implementing CP. It evaluates CP implementation results by clinicians from the doctors' perspective and the evaluation of doctors' returns. According to Dunn \& Stephens on job satisfaction, employee job satisfaction is determined by the gap between the employee's reward and the expected return. The smaller the gap is, the higher the level of job satisfaction is. This equates to what the implementation of $\mathrm{CP}$ brings to doctors, whether it improves doctors' work efficiency, increases doctors' income, or improves the doctor-patient relationship. 
Table 6 Convergent Validity Test

\begin{tabular}{|c|c|c|c|c|}
\hline Constructs & Items & $\begin{array}{l}\text { Factor } \\
\text { Loadings }\end{array}$ & AVE & CR \\
\hline $\begin{array}{l}\text { Organization } \\
\text { support }\end{array}$ & $\begin{array}{l}\text { Q1 } \\
\text { Q2 } \\
\text { Q3 } \\
\text { Q4 } \\
\text { Q5 } \\
\text { Q6 } \\
\text { Q7 } \\
\text { Q8 } \\
\text { Q9 }\end{array}$ & $\begin{array}{l}0.809 \\
0.742 \\
0.844 \\
0.778 \\
0.892 \\
0.824 \\
0.912 \\
0.934 \\
0.917\end{array}$ & 0.727 & 0.96 \\
\hline Process identity & $\begin{array}{l}\text { Q11 } \\
\text { Q12 } \\
\text { Q13 } \\
\text { Q14 }\end{array}$ & $\begin{array}{l}0.837 \\
0.901 \\
0.902 \\
0.858\end{array}$ & 0.766 & 0.929 \\
\hline Effect perception & $\begin{array}{l}\text { Q16 } \\
\text { Q17 } \\
\text { Q18 } \\
\text { Q19 } \\
\text { Q21 } \\
\text { Q22 } \\
\text { Q23 } \\
\text { Q24 }\end{array}$ & $\begin{array}{l}0.895 \\
0.909 \\
0.949 \\
0.943 \\
0.786 \\
0.859 \\
0.861 \\
0.864\end{array}$ & 0.783 & 0.966 \\
\hline
\end{tabular}

These perceptions directly affect doctors' job satisfaction, which then affects their attitude toward the implementation of $\mathrm{CP}$.

\section{Limitations and Implications}

The results of our study should be read in the context of certain limitations. First, the sample size was relatively small. Second, a network survey was used in the sample data collection, and the quality control of the investigation process did not have enough granularity. This might have impacted data authenticity. Third, while the scale was constructed with extensive input, it is yet to be shown conclusively that it accurately captures the clinicians' views of CP implementation. Finally, the scale applies only to clinicians, and it is not a comprehensive tool to assess $\mathrm{CP}$, nor does it apply to patients or other stakeholders involved in CP. Therefore, future studies are needed to examine the generalizability of the scale, the repeatability of participants' views on CP implementation, and the extent to which a participant's rating on the scale might change over time.

Despite these limitations, this is the first scale of its kind in China. It lays the foundation for related research and paves the way for more detailed research work in the future.

\section{Conclusion}

We developed a satisfaction scale of Chinese clinicians for $\mathrm{CP}$ implementation. The scale included three dimensions: organizational support, process identification, and effect perception. It comprehensively reflects clinicians' satisfaction perception of the organization structure, guarantee mechanism, process operation, and result evaluation of $\mathrm{CP}$ implementation from the aspects of structure, process, and results of doctors' implementation of CP. The scale has good validity, internal consistency, and item discrimination, and it can be used to evaluate clinicians' satisfaction in the implementation of CP. The scale can help medical institutions and health administrative agencies understand clinicians' job satisfaction in the implementation of CP. It can provide a reference for medical institutions to carry out $\mathrm{CP}$ management.

\section{Ethics Statement}

The study complied with the Declaration of Helsinki and was approved by the Ethics Committee Review Board of Sichuan Vocational College of Health and

Table 7 Discriminant Validity Test

\begin{tabular}{|c|c|c|c|c|c|c|c|c|}
\hline \multirow[t]{2}{*}{$\begin{array}{l}\text { Model and Statistics Paired } \\
\text { Potential Variables }\end{array}$} & \multicolumn{3}{|c|}{$\begin{array}{l}\text { Limited Model } \\
\text { (B) (Correlation } \\
\text { Coefficient }=I)\end{array}$} & \multicolumn{3}{|c|}{$\begin{array}{l}\text { Unlimited Model } \\
\text { (A) (Correlation } \\
\text { Coefficient is Free) }\end{array}$} & \multirow[t]{2}{*}{$\begin{array}{l}\Delta \text { df (Model B Minus } \\
\text { Model A) }\end{array}$} & \multirow[t]{2}{*}{$\Delta \chi^{2}$} \\
\hline & $\rho_{2}$ & df & $\chi^{2}$ & $\rho_{\mathbf{I}}$ & df & $\chi^{2}$ & & \\
\hline Organization support-process identity & I & 63 & 891.187 & 0.89 & 62 & 385.637 & I & $505.550 * * *$ \\
\hline Process identity-effect perception & I & 115 & 625.015 & 0.87 & 114 & 582.359 & I & $42.657 * * *$ \\
\hline Effect perception-process identity & 1 & 52 & 473.119 & 0.8 & 51 & 395.281 & I & $77.838^{* * *}$ \\
\hline
\end{tabular}

Note: ***Denote I\% significance level. 
Table 8 Reliability and Discrimination Test of the Scale

\begin{tabular}{|c|c|c|c|c|c|}
\hline Dimensions & Items & Cronbach's Alpha & D & Critical Ratio & CITC \\
\hline \multirow[t]{9}{*}{ Organization Support } & QI & 0.960 & 0.326 & $19.356^{* * *}$ & 0.811 \\
\hline & Q2 & & 0.330 & $18.590^{* * *}$ & 0.745 \\
\hline & Q3 & & 0.332 & $20.743 * * *$ & 0.859 \\
\hline & Q4 & & 0.277 & $16.162^{* * *}$ & 0.793 \\
\hline & Q5 & & 0.358 & $23.369 * * *$ & 0.877 \\
\hline & Q6 & & 0.403 & $23.247^{* * *}$ & 0.793 \\
\hline & Q7 & & 0.406 & $24.675^{* * *}$ & 0.877 \\
\hline & Q8 & & 0.394 & $25.854 * * *$ & 0.901 \\
\hline & Q9 & & 0.372 & $25.522 * * *$ & 0.875 \\
\hline \multirow[t]{4}{*}{ Process Identity } & QII & 0.927 & 0.254 & $\left.16.15\right|^{* * *}$ & 0.801 \\
\hline & Q12 & & 0.322 & $19.577^{* * * *}$ & 0.865 \\
\hline & Q13 & & 0.303 & 17.446 *** & 0.863 \\
\hline & Q14 & & 0.335 & $21.159 * * *$ & 0.796 \\
\hline \multirow[t]{8}{*}{ Effect Perception } & Q16 & 0.965 & 0.425 & $24.950 * * *$ & 0.868 \\
\hline & Q17 & & 0.532 & $31.393^{* * *}$ & 0.893 \\
\hline & Q18 & & 0.478 & $27 .|3| * * *$ & 0.927 \\
\hline & Q19 & & 0.503 & $28.568 * * *$ & 0.926 \\
\hline & Q21 & & 0.549 & $30.169 * * *$ & 0.776 \\
\hline & Q22 & & 0.375 & $22.197 * * *$ & 0.85 \\
\hline & Q23 & & 0.393 & $23.977^{* * *}$ & 0.853 \\
\hline & Q24 & & 0.443 & $27.592^{* * *}$ & 0.854 \\
\hline
\end{tabular}

Note: ***Denote $1 \%$ significance level.

Rehabilitation. In the implementation process of this study, each questionnaire survey was conducted after obtaining the informed consent of the respondents who agreed to have their data used in our study. All the data analyzed is anonymous.

\section{Acknowledgments}

We thank the Technological Innovation Miao Zi Project Management Office of Sichuan Province (Grant No. 2020113), Zigong Municipal Science and Technology Bureau (Grant No. 2019rkx08), Health Commission of Zigong (Grant No. 19yb032) for their financial support. We would also thank Jay Pan, Xiaojun Lin and Mengrong Zhu for their assistance. Lastly, we would like to express gratitude to EditSprings for the expert linguistic services provided. These authors are co-first authors as they contributed equally to this work: Junlong Li and Kui Shen.

\section{Disclosure}

The authors report no conflicts of interest in this work.

\section{References}

1. Rotter T, Kinsman L, James E, et al. The effects of clinical pathways on professional practice, patient outcomes, length of stay, and hospital costs: cochrane systematic review and meta-analysis. Eval Health Prof. 2012;35:3-27. doi:10.1177/0163278711407313

2. Sylvester AM, George M. Effect of a clinical pathway on length of stay and cost of pediatric inpatient asthma admissions: an integrative review. Clin Nurs Res. 2014;23:384-401. doi:10.1177/1054773813487373

3. Kalmet PHS, Koc BB, Hemmes B, et al. Effectiveness of a multidisciplinary clinical pathway for elderly patients with hip fracture: a multicenter comparative cohort study. Geriatr Orthop Surg Rehabil. 2016;7:81-85. doi:10.1177/2151458516645633

4. Nicola D. Integrated Care Pathways: A Guide to Good Practice. UK: National Leadership \& Innovation Agency for Healthcare; 2005.

5. Cheah TS. The impact of clinical guidelines and clinical pathways on medical practice: effectiveness and medico-legal aspects. Ann Acad Med Singap. 1998;27:533.

6. Chinese Ministry of Health. [Notice on pilot work of clinical pathway management]; 2009. Chinese.

7. Chinese Ministry of Health. [Guiding principles of clinical pathway management (Trial)]; 2009. Chinese.

8. Chinese National Health and Family Planning Commission. [Action plan for further improvement of medical services]; 2015. Chinese.

9. National Health Commission of the People's Republic of China. [Notice on printing and distributing clinical pathway of diseases (2019 Edition)]; 2020. Chinese.

10. Wang D, Chen Z, Zhang L. Analysis of medical workers' satisfaction and influencing factors with the implementation of clinical pathway. Chin Hosp Manag. 2014;34:31-33. 
11. Chinese Ministry of Health. [Implementation rules of evaluation standards for tertiary general hospitals (2011 Edition)]; 2011. Chinese.

12. Shi K, Guo H, Liu J. The structural dimension and scale development of enterprise employees' work well-being. J Sichuan Univ Sci Eng. 2020;35:1-17.

13. Liu Y, Zhang D, Xu Y, et al. Reliability and validity of the Chinese Version of Relational Self-esteem Scale (RSES) in Chinese Middle School Students. Chin J Clin Psychol. 2019;27:1187-1191.

14. Munro BH. Statistical Methods for Health Care Research. Lippincott; 1995.

15. Polito`hara D. Data Analysis \& Statistics for Nursing Research. Appleton \& Lange; 1996.

16. Tabachnick BG, Fidell LS. Using Multivariate Statistics (6th Ed.). Essex, England: Pearson Education Limited; 2014.

17. Kaiser HF. An index of factorial simplicity. Psychometrika. 1974;39:32-36. doi:10.1007/BF02291575

18. Pett MA, Lackey NR, Sullivan JJ. Making Sense of Factor Analysis. Thousand Oaks, CA: SAGE Publication; 2003.

19. Hobart JC, Riazi A, D L L, et al. Improving the evaluation of therapeutic interventions in multiple sclerosis: development of a patient-based measure of outcome. Health Technol Assess. 2004;8:1-60.
20. Zhang K, Wang A, Huang X, et al. Research and development of self-management rating scales for patients with heart failure. J Qingdao Univ. 2014;50:262-265.

21. Wu M. Structural Equation Modeling-Operation and Application of Amos (2nd Edition). Chongqing: Chongqing University Press; 2010.

22. Wen Z, Hou T, Herbert WM. Structural equation model testing: cutoff criteria for goodness of fit indices and chi-square test. Acta Psychol Sin. 2004;36:186-194.

23. Fornell C, Larcker DF. Evaluating structural equation models with unobservable variables and measurement error: a comment. J Mark Res. 1981;18:375-381. doi:10.1177/002224378101800313

24. Bentler PM, Bonett DG. Significance tests and goodness of fit in the analysis of covariance structures. Psychol Bull. 1980;88:588-606. doi:10.1037/0033-2909.88.3.588

25. Wu M. Structural Equation Model - Advanced Amos Practice. Chongqing: Chongqing University Press; 2013.

26. Devellis RF. Scale Development: Theory and Applications (Applied Social Research Methods Series, Vol. 26). Newbury Park: Sage; 1991.

27. Özdemir K, Menekşe D, Çınar N. Development of obsessive and compulsive behaviors scale of mothers in postpartum period regarding baby care: validity and reliability. Perspect Psychiatr Care. 2020;56:379-385. doi:10.1111/ppc.12445
Risk Management and Healthcare Policy

\section{Publish your work in this journal}

Risk Management and Healthcare Policy is an international, peerreviewed, open access journal focusing on all aspects of public health, policy, and preventative measures to promote good health and improve morbidity and mortality in the population. The journal welcomes submitted papers covering original research, basic science, clinical \& epidemiological studies, reviews and evaluations, guidelines, expert opinion and commentary, case reports and extended reports. The manuscript management system is completely online and includes a very quick and fair peer-review system, which is all easy to use. Visit http://www.dovepress.com/testimonials.php to read real quotes from published authors. 